\title{
Isotope-Labeled Cross-Linkers and Fourier \\ Transform Ion Cyclotron Resonance \\ Mass Spectrometry for Structural Analysis \\ of a Protein/Peptide Complex
}

\author{
Christian Ihling, ${ }^{+*}$ Andreas Schmidt, ${ }^{+*}$ Stefan Kalkhof, \\ and Daniela M. Schulz \\ Biotechnological-Biomedical Center, Faculty of Chemistry and Mineralogy, University of Leipzig, Leipzig, \\ Germany
}

Christoph Stingl and Karl Mechtler

Institute of Molecular Pathology, Vienna, Austria

\author{
Michael Haack and Annette G. Beck-Sickinger \\ Department of Bioscience, Pharmacy, and Psychology, Institute of Biochemistry, University of Leipzig, \\ Leipzig, Germany
}

Dermot M. F. Cooper

Department of Pharmacology, University of Cambridge, Cambridge, United Kingdom

\section{Andrea Sinz}

Biotechnological-Biomedical Center, Faculty of Chemistry and Mineralogy, University of Leipzig, Leipzig, Germany

For structural studies of proteins and their complexes, chemical cross-linking combined with mass spectrometry presents a promising strategy to obtain structural data of protein interfaces from low quantities of proteins within a short time. We explore the use of isotope-labeled cross-linkers in combination with Fourier transform ion cyclotron resonance (FTICR) mass spectrometry for a more efficient identification of cross-linker containing species. For our studies, we chose the calcium-independent complex between calmodulin and a 25-amino acid peptide from the C-terminal region of adenylyl cyclase 8 containing an "IQ-like motif." Cross-linking reactions between calmodulin and the peptide were performed in the absence of calcium using the amine-reactive, isotope-labeled $\left(d_{0}\right.$ and $\left.d_{4}\right)$ cross-linkers BS $^{3}$ (bis [sulfosuccinimidyl]suberate) and $\mathrm{BS}^{2} \mathrm{G}$ (bis[sulfosuccinimidyl]glutarate). Tryptic in-gel digestion of excised gel bands from covalently cross-linked complexes resulted in complicated peptide mixtures, which were analyzed by nano-HPLC/nano-ESI-FTICR mass spectrometry. In cases where more than one reactive functional group, e.g., amine groups of lysine residues, is present in a sequence stretch, MS/MS analysis is a prerequisite for unambiguously identifying the modified residues. MS/MS experiments revealed two lysine residues in the central $\alpha$-helix of calmodulin as well as three lysine residues both in the C-terminal and $\mathrm{N}$-terminal lobes of calmodulin to be cross-linked with one single lysine residue of the adenylyl cyclase 8 peptide. Further cross-linking studies will have to be conducted to propose a structural model for the calmodulin/peptide complex, which is formed in the absence of calcium. The combination of using isotope-labeled cross-linkers, determining the accurate mass of intact cross-linked products, and verifying the amino acid sequences of cross-linked species by MS/MS presents a convenient approach that offers the perspective to obtain structural data of protein assemblies within a few days. (J Am Soc Mass Spectrom 2006, 17, 1100-1113) (C) 2006 American Society for Mass Spectrometry

Published online June 5, 2006

Address reprint requests to Dr. A. Sinz, Biotechnological-Biomedical Center, Faculty of Chemistry and Mineralogy, University of Leipzig, Linnéstrasse 3, D-04103 Leipzig, Germany. E-mail: sinz@chemie.uni-leipzig.de

* Both authors contributed equally to the present work.

+ Also at the Institute of Molecular Pathology, Vienna, Austria.
7 remendous progress has been made during the past few years in mapping interface regions between interacting proteins, which is crucial for understanding signal transduction pathways and regulation of proteins. Currently, X-ray crystallography and NMR spectroscopy are the primarily applied analytical methods to structurally characterize protein complexes. Yet, both techniques possess inherent insufficiencies: NMR spectroscopy requires rather large quantities of 
isotope-labeled $\left({ }^{13} \mathrm{C}\right.$ and $\left.{ }^{15} \mathrm{~N}\right)$ pure protein in a specific solvent, and for X-ray studies the protein has to be crystallized. An alternative strategy consists in subjecting the complex constituents to chemical cross-linking reactions, followed by a mass spectrometric analysis of the created cross-linked products [1-3]. The procedure is fast, requires only low amounts of material, and offers the opportunity to gain insight into threedimensional structures of protein complexes in solution. Matrix-assisted laser desorption/ionization timeof-flight (MALDI-TOF) [4] and electrospray ionization (ESI) [5] mass spectrometry are the methods of choice for cross-linking studies because of their high sensitivity enabling rapid analysis of the complex mixtures obtained after enzymatic digestion of the cross-linking reaction mixtures. One major shortcoming of chemical cross-linking approaches, however, is the tremendous sample complexity attributable to the wide variety of cross-linked products that can be created during the cross-linking reaction. To circumvent this disadvantage, a number of different strategies have been developed that have in common to facilitate identification of cross-linker containing species, e.g., by employing isotope-labeled cross-linkers [6, 7], isotope-labeled proteins [8], cleavable cross-linkers [9], fluorogenic crosslinkers [10], or cross-linkers creating a characteristic marker ion during MS/MS analysis [11]. Another strategy to selectively enrich cross-linker containing species by using trifunctional cross-linkers containing a biotin moiety has been described recently [12-14].

In the present study, we utilize isotope-labeled crosslinkers, which are employed as 1:1 mixtures of nondeuterated and four-times deuterated derivatives. Thus, interpretation of mass spectra is greatly facilitated as cross-linker containing species are easily detected based on their characteristic isotope patterns. We are implementing FTICR mass spectrometry, which offers distinct advantages for the analysis of complex biological samples, such as excellent mass resolution, ultra-high mass measurement accuracy, and high sensitivity [15, 16] to evaluate its use in the area of cross-linking. Top-down approaches employing FTICR-MS for analyzing cross-linked products have been described by other groups [17-19] but, so far, that strategy has been exclusively employed to determine low-resolution three-dimensional structures of proteins from intramolecular cross-linking experiments. Our aim is to analyze the cross-linked species in a bottom-up approach, in which the cross-linked products are enzymatically or chemically digested before an FTICR-MS analysis is performed on the peptide mixtures $[20,21]$. Therefore, the approach has the potential to be applied to investigate even large protein assemblies-given that the cross-linked species can easily be discriminated from underivatized peptides, e.g., by isotope-labeling. In the present study, we are making use of an FTICR mass spectrometer equipped with a linear ion trap in front of the ICR cell, which offers the possibility to conveniently acquire MS/MS data during LC/MS analysis.
As a model system to demonstrate the feasibility of our approach, we chose the complex between calmodulin and a peptide derived from the C-terminal region of adenylyl cyclase 8 (AC8) that is created in the absence of calcium. CaM is an acidic protein comprised of 148 amino acids, which belongs to the family of EF-hand proteins, and is found ubiquitously in animals, plants, fungi, and protozoa [22]. CaM/peptide complexes have been used frequently in our group for developing and improving chemical cross-linking strategies [12, 20,21], as a wealth of structural data is available for the various $\mathrm{CaM} /$ target complexes (http://calcium.uhnres.utoronto. $\mathrm{ca} / \mathrm{ctdb} /)$.

AC8 belongs to the family of adenylyl cyclases, which are important signalling proteins, possessing two distinct CaM binding sites [23]: one calcium-dependent binding site is located at its N-terminus, whereas a so-called "IQ-like motif" is located at its C-terminus. "IQ-like motifs" are well known to bind to CaM in a $\mathrm{Ca}^{2+}$-dependent as well as a $\mathrm{Ca}^{2+}$-independent manner [24]. Therefore, we chose the complex between CaM, and a peptide derived from the C-terminal region of AC8, to be well suited for demonstrating our strategy using isotope-labeled cross-linkers combined with high-resolution mass spectrometry.

A 25-amino acid peptide with amidated C- terminus comprising the "IQ-like motif" of AC8 was synthesized and subjected to chemical cross-linking with CaM using the two amine-reactive, isotope-labeled cross-linkers $\mathrm{BS}^{3}$ (bis[sulfosuccinimidyl]suberate) and $\mathrm{BS}^{2} \mathrm{G}$ (bis[sulfosuccinimidyl]glutarate) in the absence of calcium. In a previous publication, we had conducted structural studies on the CaM/AC8 peptide complex that is created in the presence of calcium using isotope-labeled cross-linkers and FTICR mass spectrometry [25]. However, in this earlier study, we did not perform MS/MS experiments, which are essential for pinpointing the cross-linked amino acids as well as for verification of the amino acid sequences of the created cross-linked products. In that respect, the present study extends our initial studies using isotope-labeled cross-linkers and high-resolution mass spectrometry for a structural analysis of protein complexes.

The combination of using isotope-labeled crosslinkers, determining the accurate mass of the intact cross-linked products, and verifying the amino acid sequences of cross-linked species by MS/MS presents a convenient approach that offers the perspective to obtain structural data of protein assemblies within a few days.

\section{Experimental}

\section{Materials}

Bovine brain CaM was obtained from Calbiochem (Schwalbach am Taunus, Germany) and used without further purification. The purities of $\mathrm{CaM}$ and the AC8 peptide were checked by HPLC, ESI-FTICR and 
MALDI-TOF mass spectrometry, and SDS-PAGE. The isotope-labeled $\left(d_{0}\right.$ and $\left.d_{4}\right)$ cross-linkers $\mathrm{BS}^{3}$ and $\mathrm{BS}^{2} \mathrm{G}$ were a generous gift from Pierce (Rockford, IL). Trypsin (sequencing grade) was obtained from Roche Diagnostics (Mannheim, Germany). LHRH (luteinizing hormone releasing hormone), 2,5-dihydroxybenzoic acid, and proteins for MALDI-TOF-MS calibration were purchased from Sigma (Taufkirchen, Germany). Chemicals were obtained from Sigma at the highest available purity. Nano-HPLC solvents were spectroscopic grade (Uvasol, VWR, Darmstadt, Germany). Water was purified with a Direct-Q5 water purification system (Millipore, Eschborn, Germany).

\section{AC8 Peptide Synthesis}

The AC8 peptide was synthesized by solid-phase peptide synthesis using the automated multiple peptide synthesizer Syro II (MultiSyntech, Witten, Germany). The peptide chain was synthesized by Fmoc/tert-butyl strategy applying a double coupling procedure with a ten-fold excess of amino acid, $\mathrm{HOBt}$, and DIC in DMF for $40 \mathrm{~min}$ twice. $\mathrm{N}^{\alpha}$-Fmoc-protected amino acids and Rink amid resin (polymer) were purchased from Novabiochem (Läufelfingen, Switzerland), HOBt and DIC from Iris Biotech (Marktredwitz, Germany), and DMF from BioSolve (Valkenswaard, The Netherlands). Fmoc deprotection was accomplished by $40 \%$ piperidine in DMF for 3 min, followed by 20\% piperidine in DMF for $7 \mathrm{~min}$, and finally by $40 \%$ piperidine in DMF for $5 \mathrm{~min}$. Removal of the amino acid side-chain protecting groups and cleavage of the peptide from the resin were accomplished simultaneously by using TFA/thioanisole/thiocresol $(90 / 5 / 5$, vol/vol) for $3 \mathrm{~h}$. The deprotected peptides were allowed to precipitate for $15 \mathrm{~min}$ in ice-cold diethyl ether. The suspension was centrifuged at $5{ }^{\circ} \mathrm{C}$, the diethyl ether was decanted, and the peptide was suspended in fresh diethyl ether. The peptide was washed by repeated centrifugation, decanting, and suspending the peptide in diethyl ether. Finally, the peptide was dissolved in tert-butyl alcohol/water (1:3, vol/vol) and lyophilized. Piperidine, tert-butyl alcohol as well as the chemicals for cleavage were purchased from Fluka (Taufkirchen, Germany).

\section{Cross-Linking Reactions}

For cross-linking experiments with the homobifunctional cross-linking reagents $\mathrm{BS}^{3}-d_{0} / d_{4}$ and $\mathrm{BS}{ }^{2} \mathrm{G}-d_{0} / d_{4}$, an aqueous $\mathrm{CaM}$ stock solution $(1 \mathrm{mg} / \mathrm{ml})$ was diluted with $20 \mathrm{mM}$ Hepes buffer ( $\mathrm{pH}$ 7.5) containing $1 \mathrm{mM}$ EGTA to give solutions containing CaM at a concentration of $10.6 \mu \mathrm{M}$ (volume $964 \mu \mathrm{l}$ ). After an incubation time of $10 \mathrm{~min}, 28 \mu \mathrm{l}$ of an AC8 peptide solution (1 $\mathrm{mg} / \mathrm{ml}$ ) were added. The mixture was incubated at room temperature for $30 \mathrm{~min}$. The cross-linking reactions were started by adding $8 \mu \mathrm{l}$ of solutions containing either $\mathrm{BS}^{3}-d_{0} / d_{4}$ or $\mathrm{BS}{ }^{2} \mathrm{G}-d_{0} / d_{4}$ (each in a 1:1 mixture of $d_{0}$ and $d_{4}$ reagent at concentrations of $62.5 \mathrm{mM}, 125$
$\mathrm{mM}$, or $250 \mathrm{mM}$ in DMSO), thus yielding 50-, 100-, and 200 -fold molar excesses of cross-linker over the protein/peptide concentration. One solution was prepared without adding cross-linker solution, but $8 \mu$ l of DMSO were added instead. The reaction mixtures were incubated at room temperature, and $200-\mu 1$ aliquots were taken after $5 \mathrm{~min}, 15 \mathrm{~min}, 30 \mathrm{~min}, 60 \mathrm{~min}$, and $120 \mathrm{~min}$. The reactions were terminated by adding $20 \mu \mathrm{l}$ of a 220 $\mathrm{mM} \mathrm{NH}_{4} \mathrm{HCO}_{3}$ (final concentration $20 \mathrm{mM}$ ) solution to each aliquot. The solutions were desalted using Microcon-YM-3 filters (Millipore) and stored at $-20^{\circ} \mathrm{C}$ before MALDI-TOF-MS and SDS-PAGE were conducted.

\section{SDS-PAGE and Enzymatic Proteolysis}

Following separation of the reaction mixtures by onedimensional SDS-PAGE (15\%, Coomassie staining [26]), the bands of interest were excised and in-gel digested as described previously [27]. Trypsin (50 ng/ $\mu \mathrm{L})$ was used as digestion enzyme for all samples. Depending on the volume of the gel pieces, between 6 and $8 \mu$ l of enzyme solution were added. The gel pieces were covered with $50 \mathrm{mM} \mathrm{NH}{ }_{4} \mathrm{HCO}_{3}$ solution and incubated at $37^{\circ} \mathrm{C}$ for $16 \mathrm{~h}$.

\section{MALDI-TOF Mass Spectrometry}

MALDI-TOF mass spectrometry of the cross-linking reaction mixtures was performed on a Voyager DE RP Biospectrometry Workstation (Applied Biosystems, Foster City, CA) equipped with a nitrogen laser (337 $\mathrm{nm}$ ). The instrument was run in positive ionization mode and measurements were performed in the linear mode (detection range $\mathrm{m} / \mathrm{z} 13,000$ to 45,000 ) using 2,5-dihydroxybenzoic acid as matrix. A saturated matrix solution was prepared in $30 \%$ ( $\mathrm{vol} / \mathrm{vol})$ acetonitrile, $69.9 \%$ (vol/vol) water, and 0.1\% (vol/vol) TFA. Samples were prepared using the dried droplet method by spotting $0.5 \mu \mathrm{l}$ of matrix solution and $0.5 \mu \mathrm{l}$ of sample solution onto the target. Spectra from 100 to 300 laser shots were accumulated to one spectrum. The instrument was calibrated using cytochrome $c$ $\left([\mathrm{M}+\mathrm{H}]^{+}{ }_{\text {average }}\right.$ at $\left.\mathrm{m} / \mathrm{z} 12,361\right)$ and myoglobin $\left([\mathrm{M}+\mathrm{H}]^{+}\right.$average at $\left.m / z 16,952\right)$. Data acquisition and data processing were performed using the Voyager software version 5.1 and the Data Explorer software version 4.0 (Applied Biosystems).

\section{Nano-HPLC/Nano-ESI-FTICR Mass Spectrometry}

Peptide mixtures from enzymatic digests were separated by nano-HPLC on an Ultimate Nano-LC system (Dionex, Idstein, Germany) equipped with a Switchos II column switching module and a Famos Micro Autosampler with a 20- $\mu$ l sample loop. Samples were injected by the autosampler and concentrated on a trapping column (PepMap, C18, $5 \mathrm{~mm} \times 300 \mu \mathrm{m}, 3 \mu \mathrm{m}$, $100 \AA$, Dionex, Idstein, Germany) with water containing 
$0.1 \%$ formic acid at flow rates of $20 \mu \mathrm{l} / \mathrm{min}$. After $3 \mathrm{~min}$ for desalting, the peptides were eluted onto the separation column (PepMap, C18, $150 \mathrm{~mm} \times 75 \mu \mathrm{m}, 3 \mu \mathrm{m}, 100$ $\AA$, Dionex), which had been equilibrated with $95 \% \mathrm{~A}$ (Solvent A: water containing $0.1 \%$ formic acid). Peptides were separated using the following gradient: $0-30$ min: 5-50\% B, 30-31 min: 50-95\% B, 31-45 min: 95\% B (Solvent B: acetonitrile containing $0.1 \%$ formic acid) at flow rates of $200 \mathrm{nl} / \mathrm{min}$ and detected based on their UV absorptions at 214 and $280 \mathrm{~nm}$.

The nano-HPLC system was coupled on-line to an APEX II FTICR mass spectrometer equipped with a 7 tesla superconducting magnet (Bruker Daltonics, Billerica, MA) and a nano-electrospray ionization source (Agilent Technologies, Waldbronn, Germany). For nano-ESI-MS, coated fused-silica PicoTips (tip ID $8 \mu \mathrm{m}$, New Objective, Woburn, MA) were applied. The capillary voltage was set to $-1400 \mathrm{~V}$. Mass spectral data were acquired in the broadband mode over an $\mathrm{m} / \mathrm{z}$ range of 400 to 2000 with $256 \mathrm{k}$ data points, four scans were accumulated per spectrum, and 400 spectra were recorded for each LC/MS run. MS data acquisition was initialized with a trigger signal from the HPLC system 7 min after initiation of the LC gradient. Data were acquired over $34.5 \mathrm{~min}$. Calibration of the instrument was performed with CID fragments (capillary exit voltage $200 \mathrm{~V}$ ) of the LHRH peptide. Data acquisition and data processing were performed using the XMASS software, version 7.0.2 (Bruker Daltonics). Before Fourier transformation the time-domain signals were doubly zero filled, followed by apodization with a sine function. Four hundred single spectra were projected into one final mass spectrum using the "Projection" tool in the XMASS software [28]. The obtained spectra were internally recalibrated using autolytic peptide signals from trypsin. The XMASS software, version 7.0.2, was used for manual generation of peak lists containing the neutral monoisotopic peptide masses. An in-house software ("IsoFind") was employed to search for signals exhibiting a mass difference of $4 \mathrm{u}$ and to calculate the ratios of the respective signal intensities.

\section{MS/MS Analysis}

Products of the cross-linking reactions conducted with $\mathrm{BS}^{2} \mathrm{G}$ (gel bands $\mathrm{D}, 30,60,120 \mathrm{~min}$ reaction times, Figure 2), were additionally analyzed by MS/MS experiments. The peptide mixtures resulting from the tryptic in-gel digests were separated by C18-RP-chromatography on a nano-HPLC system (Ultimate 3000, Dionex; pre-column: PepMap, C18, $5 \mathrm{~mm} \times 300 \mu \mathrm{m}, 3 \mu \mathrm{m}, 100$ $\AA$, Dionex; separation column: PepMap, C18, $150 \mathrm{~mm} \times$ $75 \mu \mathrm{m}, 3 \mu \mathrm{m}, 100 \AA$, Dionex; solvents A: $5 \%$ acetonitrile, $0.1 \%$ formic acid in water, B: $80 \%$ acetonitrile, $0.08 \%$ formic acid in water) using a gradient from $0 \%$ B to $60 \%$ $\mathrm{B}$ in $90 \mathrm{~min}$ followed by isocratic elution with $90 \%$ B for $3 \mathrm{~min}$. An LTQ-FT mass spectrometer (Thermo Electron, Bremen, Germany) with a $7 \mathrm{~T}$ magnet, equipped with a nano-ESI source (Proxeon Biosystems, Odense, (a)

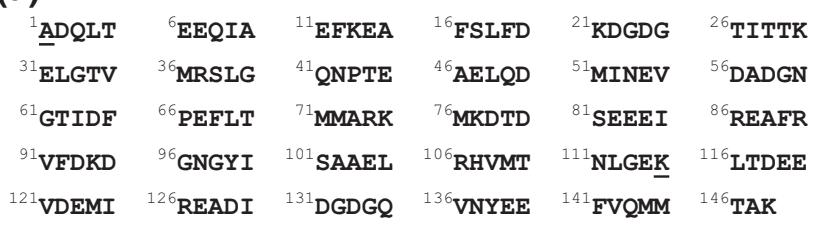

(b)

\section{${ }^{1}$ YSLAA ${ }^{6}$ VVLGL ${ }^{11}$ VQSLN ${ }^{16}$ RQRQK ${ }^{21}$ QLLNE-NH}

Figure 1. Amino acid sequences of (a) CaM and (b) AC8 peptide. CaM is N-acetylated (Ac-Ala) and contains a trimethylated lysine in position 115 (the modified amino acids Ala-1 and Lysine 115 are underlined). The "IQ-like motif" in the AC8 peptide comprises amino acids 11-16 (VQSLNR underlined).

Denmark; emitter: distal coated PicoTips, tip ID $15 \mu \mathrm{m}$, New Objective) was on-line coupled to the nano-HPLC system. MS data were acquired over $100 \mathrm{~min}$ in datadependent MS2 mode: each high-resolution full scan $(\mathrm{m} / \mathrm{z} 300$ to 2000 , resolution at $\mathrm{m} / \mathrm{z} 400$ was set to $100.000)$ in the ICR cell was followed by 10 product ion scans in the linear trap for the 10 most intense signals in the full-scan mass spectrum (isolation window $3 \mathrm{u}$ ). Dynamic exclusion (exclusion duration $20 \mathrm{~s}$, exclusion window $\pm 5 \mathrm{ppm}$ ) was enabled to allow detection of less abundant ions. Data analysis was performed using the SEQUEST search algorithm (BioWorks 3.2, Thermo Electron).

\section{Identification of Cross-Linked Products}

Cross-linked products were identified using the GPMAW (General Protein Mass Analysis for Windows) software, versions 6.01 and 6.2 (Lighthouse Data, Odense, Denmark) (available at: http://welcome.to/ gpmaw) [29] and the ExPASy Proteomics tools in the Swiss-Prot Database (available at: www.expasy.ch). Proteolytic cleavages at modified amino acids, such as the trimethylated K115 in CaM as well as amino acids modified by cross-linking reagents were excluded. The $\mathrm{N}$-terminus of CaM was excluded from possible crosslinking as it is acetylated (Figure 1).

\section{Structure of Calcium-Free CaM}

The NMR structure of apo Cam $\left(\mathrm{Ca}^{2+}\right.$-free $\left.\mathrm{CaM}\right)$ is deposited in the RCSB Protein Data Bank (http:// www.rcsb.org/pdb/) under the entry " $1 \mathrm{DMO}^{\prime}$ ". The structure was visualized using the VMD-XPLOR visualization package (available at: http://vmd-xplor.cit. nih.gov).

\section{Results and Discussion}

\section{Characterization of CaM and AC8 Peptide}

A prerequisite for successfully conducting cross-linking experiments consists in an in-depth characterization of 
Table 1. Chemical structures and spacer lengths of the amine-reactive, homobifunctional, and isotope-labeled $\left(d_{0}\right.$ and $\left.d_{4}\right)$ cross-linking reagents $\mathrm{BS}^{3}$ and $\mathrm{BS}^{2} \mathrm{G}$

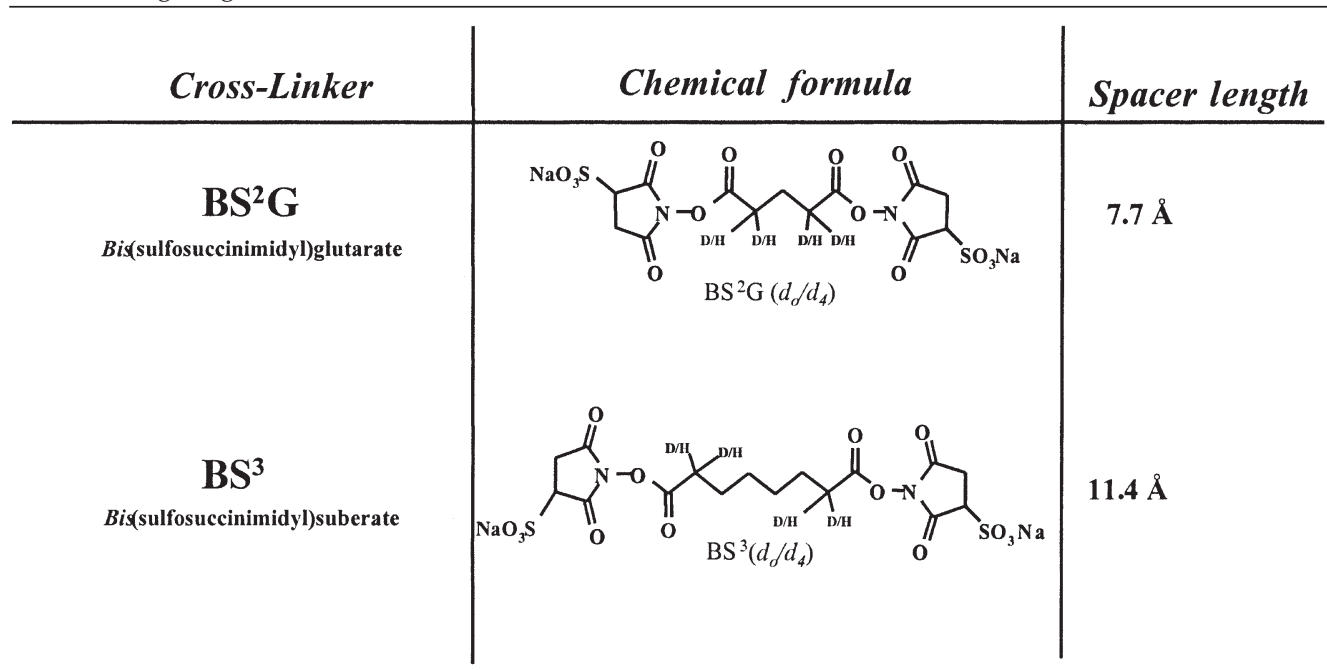

the proteins regarding their post-translational modifications, splice variants, or amino acid exchanges. The characterization of CaM has been described in detail in previous publications of our group [20,21]. Exact mass measurements, after spectral deconvolution, of the intact protein and peptide performed by ESI-FTICRMS yielded a most abundant mass of 16,790.921 u for CaM (simulated: 16,790.884 u, $\Delta \mathrm{m}=0.037 \mathrm{u}, 2.1 \mathrm{ppm}$ ) and a monoisotopic mass of $2838.650 \mathrm{u}$ for the AC8 peptide (calculated: $2838.619 \mathrm{u}, \Delta \mathrm{m}=0.031 \mathrm{u}, 10.9 \mathrm{ppm}$ ). The amino acid sequences of CaM and AC8 peptide are presented in Figure 1.

\section{Cross-Linking Reactions}

Cross-linking experiments between CaM and the AC8 peptide were conducted as described in the Experimental section. The homobifunctional, amine-reactive crosslinking reagents $\mathrm{BS}^{3}-d_{0} / d_{4}$ and $\mathrm{BS}^{2} \mathrm{G}-d_{0} / d_{4}$ (Table 1 ) were used for cross-linking experiments. Homobifunctional cross-linking reagents contain two identical functional groups on either side of the molecule that are separated by a spacer bridging a defined distance [30]. The homobifunctional sulfo-NHS esters $\mathrm{BS}^{3}$ and $\mathrm{BS}^{2} \mathrm{G}$ are highly reactive towards primary amine groups, but are also susceptible to hydrolysis. Upon cross-linking, $\mathrm{BS}^{3}$ and $\mathrm{BS}^{2} \mathrm{G}$ produce amide bond cross-linked molecules causing mass shifts of $138.077 \mathrm{u}\left(\mathrm{BS}^{3}-d_{0}\right)$ and $96.030 \mathrm{u}\left(\mathrm{BS}^{2} \mathrm{G}-d_{0}\right)$, respectively, whereas peptides modified with partially hydrolyzed cross-linkers exhibit mass increases of $156.092 \mathrm{u}\left(\mathrm{BS}^{3}-d_{0}\right)$ and $114.045 \mathrm{u}$ $\left(\mathrm{BS}^{2} \mathrm{G}-d_{0}\right)$, respectively. 1:1 mixtures of nondeuterated $\left(d_{0}\right)$ and four-times deuterated $\left(d_{4}\right)$ reagents were employed to facilitate identification of cross-linker containing species based on their characteristic isotope doublet with a mass difference of $4.025 \mathrm{u}$ in the deconvoluted ESI-FTICR mass spectra.

\section{SDS-PAGE}

After the cross-linking reactions, reaction mixtures were separated by one-dimensional SDS-PAGE and the gels were stained with Coomassie Brilliant Blue. CaM exhibited three bands on the gel (one intense and two faint bands, Figure 2). We assume that-despite using EGTA as calcium-complexing agent-a minor part of CaM molecules are present in different calcium-loaded states, exhibiting different mobilities on the gel. As shown for the cross-linking reaction mixture obtained with $\mathrm{BS}{ }^{2} \mathrm{G}-d_{0} / d_{4}$ (Figure 2 ), an intense band at $\sim 17 \mathrm{kDa}$ probably represents intramolecularly cross-linked CaM (Band C, Figure 2). Bands of nonreacted CaM (Band B,

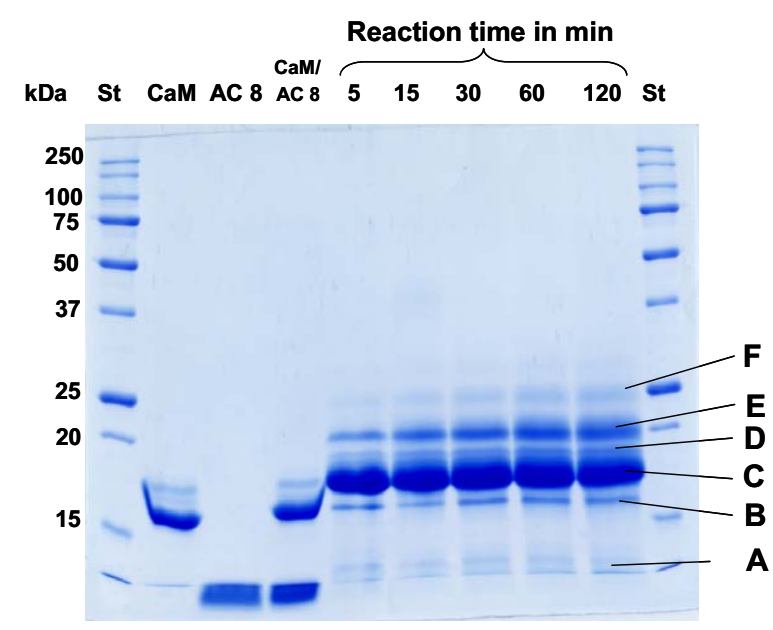

Figure 2. SDS-PAGE of CaM/AC8 peptide cross-linking reaction mixture with $\mathrm{BS}^{2} \mathrm{G}-d_{0} / d_{4}$ (100-fold excess, $1 \mathrm{mM}$ EGTA), reaction times 5 to $120 \mathrm{~min}$. St: molecular weight standard. Band A: intramolecularly cross-linked AC8 peptide; Band B: CaM; Band C: intramolecularly cross-linked CaM; Bands D and E: CaM/AC8 peptide complexes (1:1); Band F: CaM/AC8 peptide (1:2) complex. 


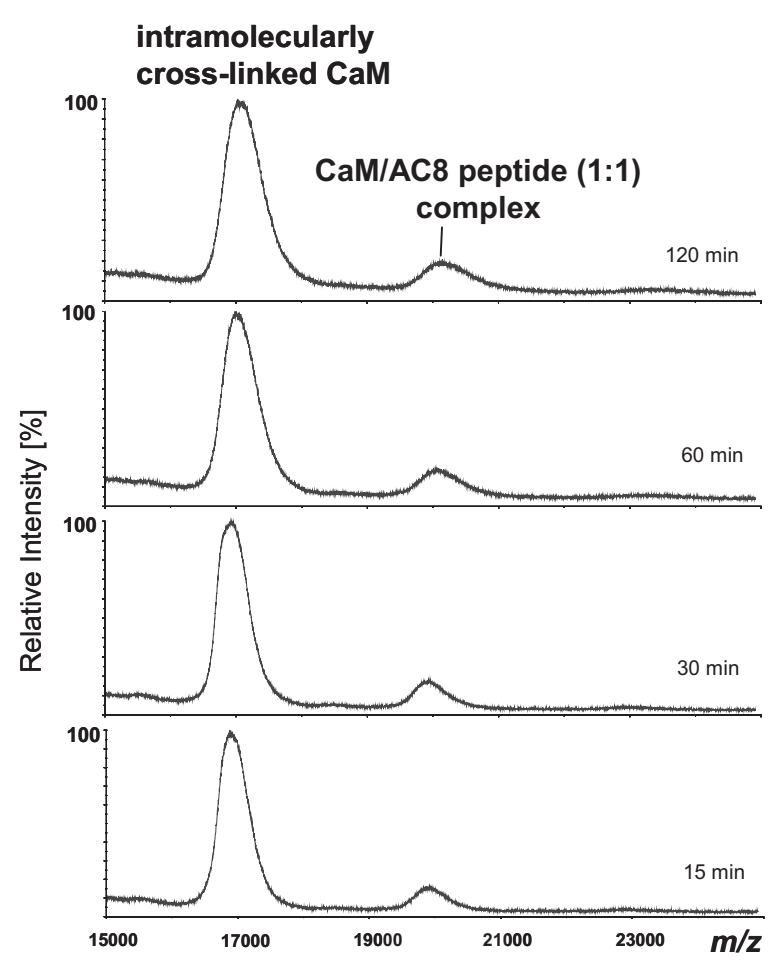

Figure 3. MALDI-TOF mass spectra of CaM/AC8 peptide crosslinking reaction mixtures obtained with $\mathrm{BS}^{2} \mathrm{G}$ (100-fold excess over protein / peptide concentration), 1 mM EGTA.

Figure 2) and intramolecularly cross-linked AC 8 peptide (Band A, Figure 2) are also visible on the gel. Two bands migrating at $\sim 19$ and $20 \mathrm{kDa}$ were assigned to CaM/AC8 peptide (1:1) complexes (Bands D and E) exhibiting different mobilities on the gel due to the presence of differently cross-linked species (Figure 2). Also, formation of a CaM/AC8 peptide (1:2) complex was observed (Band F, Figure 2) as was visualized by the presence of a faint gel band migrating at $\sim 25 \mathrm{kDa}$. Aggregation of proteins caused by excessive crosslinking was not observed for any of the cross-linking reagents, as no gel bands were visible in the higher mass range.

\section{MALDI-TOF Mass Spectrometry}

MALDI-TOF-MS was employed to estimate the extent of chemical cross-linking over the course of the crosslinking reaction. For $\mathrm{BS}^{2} \mathrm{G}$, formation of a CaM/ $\mathrm{AC} 8$ peptide (1:1) complex at $m / z \sim 19,900$ was observed with the signal intensity slightly increasing with increasing reaction time (Figure 3). From the $\sim 300 \mathrm{u}$-mass shift of the CaM signal (signal at $\mathrm{m} / \mathrm{z} \sim 17,100$ instead of $\mathrm{m} / \mathrm{z}$ 16,790 for noncross-linked CaM), the incorporation of three $\mathrm{BS}^{2} \mathrm{G}$ molecules per CaM molecule was estimated (Figure 3). The broadness of the signal for intramolecularly cross-linked CaM gives a first hint on the variety of intramolecular modifications that have been created in the course of the cross-linking reaction.

\section{Analysis of Cross-Linked Products}

Following SDS-PAGE separation of the cross-linking reaction mixtures, bands of the cross-linked CaM/AC8 peptide (1:1) complexes (Bands D and E, Figure 2) as well as bands originating from intramolecularly crosslinked CaM (Band C, Figure 2) were excised from the gel and subjected to enzymatic in-gel digestion with trypsin. CaM/AC8 peptide (1:2) complexes that were observed in SDS-PAGE (Band F, Figure 2) were assumed to be artifacts and were not investigated further. Now, we cannot rule out that CaM/AC8 peptide (1:2) complexes are also created in vivo. The band corresponding to intramolecularly cross-linked CaM could either originate from unbound $\mathrm{CaM}$ or, alternatively, it represents the CaM conformation within the complex, which dissociates during SDS-PAGE separation as it is not covalently attached to its binding partner by a cross-linker molecule. The intricate peptide mixtures resulting from in-gel digestion were analyzed by nanoHPLC/nano-ESI-FTICR mass spectrometry with respect to the presence of intra- and intermolecular crosslinked products as well as peptides, which are modified by a partially hydrolyzed cross-linker.

\section{Cross-Linked Products Obtained with BS ${ }^{2} G-d_{0} / d_{4}$}

$\mathrm{BS}^{2} \mathrm{G}$ was employed for conducting cross-linking reactions as a 1:1 mixture with its deuterated derivative $\left(d_{4}\right)$ (Table 1). Thus, an additional criterion for the identification of cross-linked products is introduced, as every species containing one cross-linker molecule should exhibit a doublet with a distance of $4.025 \mathrm{u}$ in the deconvoluted ESI-FTICR mass spectra. One intermolecular cross-linked product was identified during our first set of experiments from band E (Figure 2), in which amino acid sequence 75-86 (central $\alpha$-helix) of CaM is connected with amino acids $17-25$ of AC8 peptide (Table 2). Lys-20 is the exclusive reaction site in the respective AC8 sequence that has reacted with Lys-75 or Lys-77 of CaM. For clarification, which of the lysine residues at position 75 or 77 in CaM had reacted, MS/MS experiments were conducted (see below). The deconvoluted ESI-FTICR mass spectrum, from which this cross-linked product was identified, is presented in Figure 4 with the inset showing the magnified signal of the identified intermolecular cross-linked product. The doublet of isotope patterns with a mass difference of $4.025 \mathrm{u}$ caused by using a 1:1 mixture of $d_{0^{-}}$and $d_{4}$-cross-linker greatly facilitates identification of crosslinker-containing species.

\section{Cross-Linked Products Obtained with $B S^{3}-d_{0} / d_{4}$}

As in the case of $\mathrm{BS}^{2} \mathrm{G}, \mathrm{BS}^{3}$ was employed as 1:1 mixture with its fully deuterated derivative $\left(d_{4}\right)$. With a 100 -fold excess of $\mathrm{BS}^{3}-d_{0} / d_{4}$ over protein/peptide, one intermolecular cross-linked product was identified between $\mathrm{CaM}$ and AC8 pointing to amino acids $75-86$ of $\mathrm{CaM}$ 


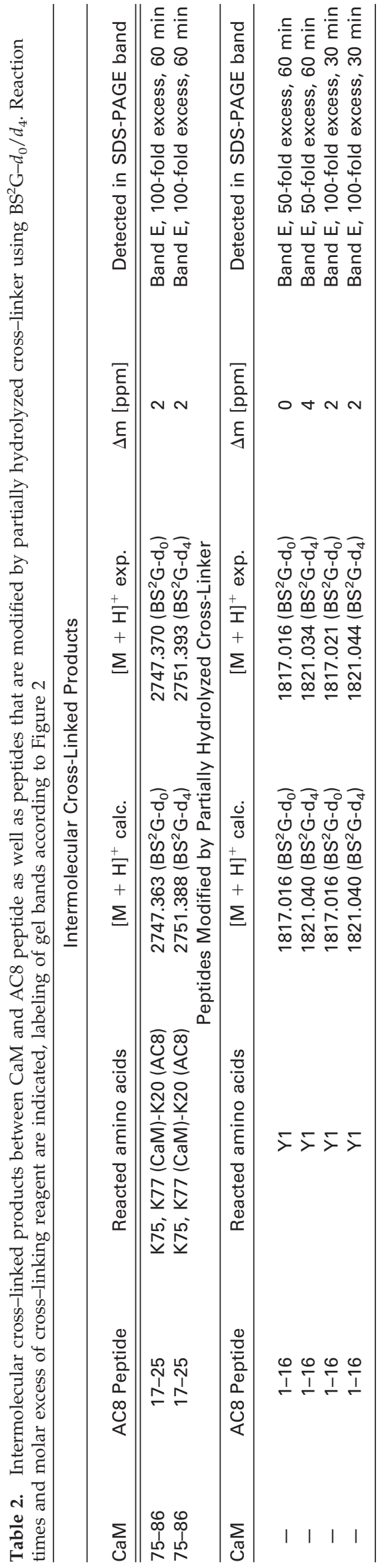

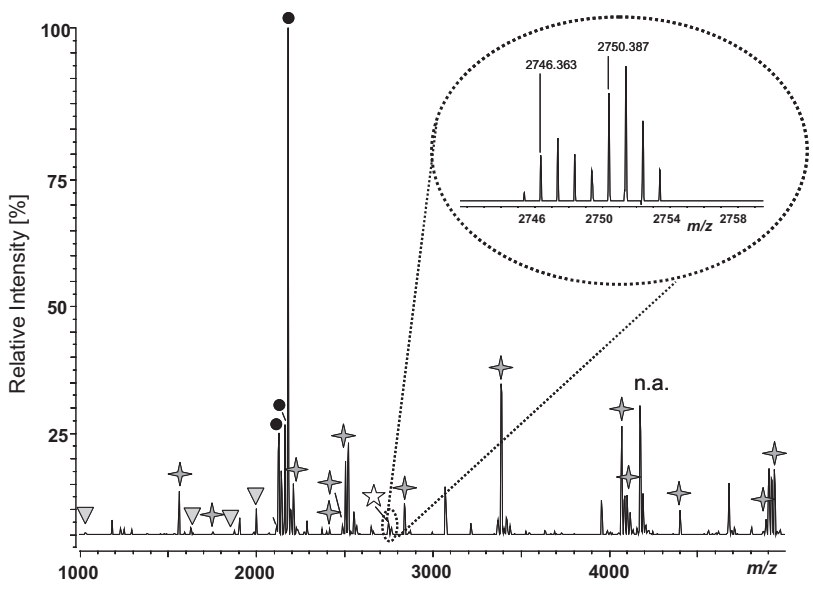

Figure 4. Deconvoluted ESI-FTICR mass spectrum of a tryptic digest of a cross-linking reaction mixture (CaM/AC8 peptide (1:1) complex created with 100 -fold excess $B S^{2} \mathrm{G}-d_{0} / d_{4}, 1 \mathrm{mM}$ EGTA, reaction time $60 \mathrm{~min}$ ). Signals of the identified cross-linked product between amino acids 75-86 of CaM and amino acids 17-25 of AC8 peptide (Table 3) are shown enlarged. Please note that neutral monoisotopic masses are given. The signal intensities of the characteristic isotope doublet are not equal, as the BS ${ }^{2} \mathrm{G}-d_{0} / d_{4}$ mixture was not exactly 1:1. Signals originating from CaM peptides (diamond), AC8 peptides (triangle), cross-linked products (open star), and autolytic peptides of trypsin (filled circle) are indicated; n.a.: signal not assigned.

and the complete AC8 peptide being connected (Table 3). In the AC8 peptide, either the $\mathrm{N}$ terminus or, more likely, the $\varepsilon$-amino group of the lysine in position 20 has reacted with one of the lysine residues in position 75 or 77 of the CaM central $\alpha$-helix.

\section{Peptides Modified by Hydrolyzed Cross-Linker}

In addition to inter- and intramolecularly cross-linked products, we observed a large number of peptides that had been modified by partially hydrolyzed $\mathrm{BS}^{3}$ or $\mathrm{BS}^{2} \mathrm{G}$ (Tables 2, 3, and 4). The modified amino acids do not yield direct information on the interface between CaM and AC8; however, they provide valuable information on the surface topology of the complex. As is readily visible from Figure 6, these residues are solventexposed in calcium-free CaM and thus, are quite easily modified by the cross-linker.

\section{Identification of Cross-Linked Amino Acids by MS/MS}

To unambiguously identify the amino acids that had actually been cross-linked, additional MS/MS experiments were conducted on the tryptic peptides of Band $\mathrm{D}$ (Figure 2), derived from cross-linking reaction mixtures that had been created using a 100-fold molar excess of $\mathrm{BS}^{2} \mathrm{G}-d_{0} / d_{4}$. MS/MS experiments yielded a wealth of information on the various cross-linked products that had been created in one single cross-linking reaction (Table 4). As far as intermolecular cross-linking 
Table 3. Intermolecular cross-linked products between CaM and AC8 peptide as well as peptides that are modified by partially hydrolyzed cross-linker using BS ${ }^{3} \mathrm{G}-d_{0} / d_{4}$. Reaction times and molar excess of cross-linking reagent are indicated, labeling of gel bands according to Figure 2. MSO: oxidized methionine

Intermolecular cross-linked products

\begin{tabular}{|c|c|c|c|c|c|c|}
\hline $\mathrm{CaM}$ & AC8 peptide & Reacted amino acids & {$[\mathrm{M}+\mathrm{H}]^{+}$calc. } & {$[\mathrm{M}+\mathrm{H}]^{+}$exp. } & $\Delta \mathrm{m}[\mathrm{ppm}]$ & Detected in SDS-PAGE band \\
\hline $75-86$ & $1-25$ & K75, K77 (CaM)-Y1, K20 (AC8) & $\begin{array}{l}4457.382 \\
\left(B S^{3}-d_{0}\right)\end{array}$ & $\begin{array}{l}4457.426 \\
\left(B S^{3}-d_{0}\right)\end{array}$ & 10 & Band $E, 100$-fold excess, $60 \mathrm{~min}$ \\
\hline $75-86$ & $1-25$ & K75, K77 (CaM)-Y1, K20 (AC8) & $\begin{array}{l}4461.407 \\
\left(\mathrm{BS}^{3}-\mathrm{d}_{4}\right)\end{array}$ & $\begin{array}{l}4461.411 \\
\left(\mathrm{BS}^{3}-\mathrm{d}_{4}\right)\end{array}$ & 1 & Band $E, 100$-fold excess, $60 \mathrm{~min}$ \\
\hline
\end{tabular}

Peptides Modified by Partially Hydrolyzed Cross-Linker

\begin{tabular}{|c|c|c|c|c|c|c|}
\hline $\mathrm{CaM}$ & AC8 Peptide & Reacted amino acids & {$[\mathrm{M}+\mathrm{H}]^{+}$calc. } & {$[\mathrm{M}+\mathrm{H}]^{+}$exp. } & $\Delta \mathrm{m}[\mathrm{ppm}]$ & Detected in SDS-PAGE band \\
\hline $1-37$ & - & $\mathrm{K} 13, \mathrm{~K} 21, \mathrm{~K} 30$ & $\begin{array}{l}4348.106 \\
\left(B S^{3}-d_{0}\right)\end{array}$ & $\begin{array}{l}4348.143 \\
\left(B S^{3}-d_{0}\right)\end{array}$ & 1 & Band C, 100-fold excess, $60 \mathrm{~min}$ \\
\hline $1-37$ & - & $\mathrm{K} 13, \mathrm{~K} 21, \mathrm{~K} 30$ & $\begin{array}{l}4352.131 \\
\left(\mathrm{BS}^{3}-\mathrm{d}_{4}\right)\end{array}$ & $\begin{array}{l}4352.143 \\
\left(B S^{3}-d_{4}\right)\end{array}$ & 3 & Band C, 100-fold excess, $60 \mathrm{~min}$ \\
\hline $91-126$ & - & K94 & $\begin{array}{l}4293.105 \\
\left(B S^{3}-d_{0}\right)\end{array}$ & $\begin{array}{l}4293.108 \\
\left(B S^{3}-d_{0}\right)\end{array}$ & 1 & Band C, 100-fold excess, $60 \mathrm{~min}$ \\
\hline $91-126$ & - & K94 & $\begin{array}{l}4297.130 \\
\left(B S^{3}-d_{4}\right)\end{array}$ & $\begin{array}{l}4297.149 \\
\left(B S^{3}-d_{4}\right)\end{array}$ & 5 & Band C, 100-fold excess, $60 \mathrm{~min}$ \\
\hline $91-126$ & - & K94 & $\begin{array}{l}4293.105 \\
\left(B S^{3}-d_{0}\right)\end{array}$ & $\begin{array}{l}4293.076 \\
\left(B S^{3}-d_{0}\right)\end{array}$ & 7 & Band $E, 50$-fold excess, $60 \mathrm{~min}$ \\
\hline $91-126$ & - & K94 & $\begin{array}{l}4297.130 \\
\left(\mathrm{BS}^{3}-\mathrm{d}_{4}\right)\end{array}$ & $\begin{array}{l}4297.105 \\
\left(\mathrm{BS}^{3}-\mathrm{d}_{4}\right)\end{array}$ & 6 & Band $E, 50$-fold excess, $60 \mathrm{~min}$ \\
\hline $91-126$ & - & K94 & $\begin{array}{l}4309.100 \\
\left(\mathrm{MSO}, \mathrm{BS}^{3}-\mathrm{d}_{0}\right)\end{array}$ & $\begin{array}{l}4309.070 \\
\left(\mathrm{MSO}, \mathrm{BS}^{3}-\mathrm{d}_{0}\right)\end{array}$ & 7 & Band $E, 50$-fold excess, $60 \mathrm{~min}$ \\
\hline $91-126$ & - & K94 & $\begin{array}{l}4313.125 \mathrm{MSO} \\
\left(\mathrm{BS}^{3}-\mathrm{d}_{4}\right)\end{array}$ & $\begin{array}{l}4313.093 \\
\left(\mathrm{MSO}, \mathrm{BS}^{3}-\mathrm{d}_{4}\right)\end{array}$ & 7 & Band $E, 50$-fold excess, $60 \mathrm{~min}$ \\
\hline $91-126$ & - & K94 & $\begin{array}{l}4309.100 \\
\left(\mathrm{MSO}, \mathrm{BS}^{3}-\mathrm{d}_{0}\right)\end{array}$ & $\begin{array}{l}4309.108 \\
\left(\mathrm{MSO}, \mathrm{BS}^{3}-\mathrm{d}_{0}\right)\end{array}$ & 2 & Band C, 100-fold excess, $60 \mathrm{~min}$ \\
\hline $91-126$ & - & K94 & $\begin{array}{l}4313.125 \\
\left(\mathrm{MSO}, \mathrm{BS}^{3}-\mathrm{d}_{4}\right)\end{array}$ & $\begin{array}{l}4313.110 \\
\left(\mathrm{MSO}, \mathrm{BS}^{3}-\mathrm{d}_{4}\right)\end{array}$ & 3 & Band C, 100-fold excess, $60 \mathrm{~min}$ \\
\hline
\end{tabular}




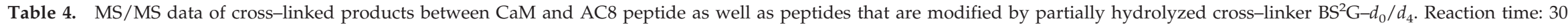

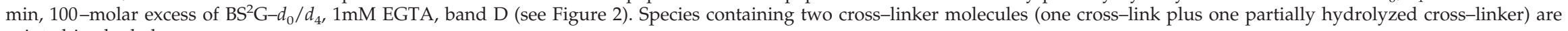
printed in shaded areas

\begin{tabular}{|c|c|c|c|c|c|c|c|c|c|c|}
\hline \multicolumn{2}{|c|}{ Cross-linked sequences } & \multicolumn{2}{|c|}{ Cross-linked residue } & \multirow{2}{*}{$\begin{array}{c}\text { Theoretical } \\
\text { precursor } \\
\text { mass } \\
{\left[\mathrm{M}+\mathrm{H}^{+}\right.}\end{array}$} & \multirow{2}{*}{$\begin{array}{c}\text { Experimental } \\
\text { precursor } \\
\text { mass }\end{array}$} & \multirow[t]{2}{*}{ Cross-linker $\mathrm{BS}^{2} \mathrm{G}$} & \multicolumn{4}{|c|}{ Identified fragment ions } \\
\hline $\mathrm{CaM}$ & AC8 peptide & CaM & AC8 peptide & & & & $\mathrm{b}$ ion series CaM & $\begin{array}{c}\text { AC } 8 \\
\text { peptide }\end{array}$ & y ion series CaM & $\begin{array}{c}\text { AC8 } \\
\text { peptide }\end{array}$ \\
\hline \multirow[t]{2}{*}{$14-30$} & $19-25$ & K21 & K20 & 2811.404 & 2811.412 & do & $3-9,11,12,14,16$ & - & $3-8,11-16$ & - \\
\hline & & & & 2815.429 & 2815.434 & d4 & $3-7,9-16$ & - & $3-12,14-16$ & - \\
\hline \multirow[t]{2}{*}{$22-30$} & $19-25$ & K30 & K20 & 1873.950 & 1873.939 & do & $3,4,6-8$ & - & $1-3,5-8$ & - \\
\hline & & & & 1877.975 & 1877.934 & d4 & $3,4,6,8$ & - & $1-3,5-8$ & - \\
\hline \multirow[t]{2}{*}{ 75-86 } & $19-25$ & K77 & K20 & 2447.208 & 2447.204 & do & $1-4,6-11$ & - & $2-11$ & - \\
\hline & & & & 2451.233 & 2451.228 & d4 & $2-11$ & - & $2-11$ & - \\
\hline \multicolumn{11}{|c|}{ Oxidation at M76 } \\
\hline \multirow[t]{2}{*}{$75-86$} & $19-25$ & K77 & K20 & 2463.207 & 2463.212 & do & $4,6,8-11$ & $2,4-6$ & $2-11$ & $2-6$ \\
\hline & & & & 2467.232 & 2467.239 & d4 4 & 3-11 & - & $2-10$ & - \\
\hline \multicolumn{11}{|c|}{ Ammonia loss and oxidation at M76 } \\
\hline \multirow[t]{2}{*}{ 75-86 } & $19-25$ & K77 & K20 & 2446.180 & 2446.174 & do & $2-11$ & - & $2-11$ & - \\
\hline & & & & 2450.205 & 2450.210 & d4 & $2-11$ & - & $2-10$ & - \\
\hline \multicolumn{11}{|c|}{ Two cross-linkers } \\
\hline 75-86 & $19-25$ & K75 & K20 & 2561.240 & 2561.244 & $2 x d 0$ & $1-8,10,11$ & - & $2-11$ & - \\
\hline $75-86$ & $19-25$ & K77 & K20 & 2561.240 & 2561.244 & $2 x d 0$ & $1-3,5,6,8-11$ & - & $2-11$ & - \\
\hline $75-86$ & $19-25$ & K75 & K20 & 2565.265 & 2565.272 & d0 K75,d4 K77 & $1-11$ & - & $2-11$ & - \\
\hline $75-86$ & $19-25$ & K75 & K20 & 2565.256 & 2565.272 & d4 K75,d0 K77 & $1-11$ & - & $2-11$ & - \\
\hline $75-86$ & $19-25$ & K77 & K20 & 2565.256 & 2565.272 & d4 K75,d0 K77 & $2-11$ & - & $2-10$ & - \\
\hline $75-86$ & $19-25$ & K77 & K20 & 2565.256 & 2565.272 & d0 K75,d4 K77 & $1-11$ & - & $2-11$ & - \\
\hline 75-86 & $19-25$ & K75 & K20 & 2569.281 & 2569.280 & $2 x d 4$ & $1,3-10$ & - & $2,4-9,11$ & - \\
\hline $75-86$ & $19-25$ & K77 & K20 & 2569.281 & 2569.280 & $2 x d 4$ & $2-8,10,11$ & - & $2-11$ & - \\
\hline \multirow[t]{2}{*}{$76-86$} & $19-25$ & K77 & K20 & 2319.113 & 2319.115 & do & $2-8,10$ & - & $2-10$ & - \\
\hline & & & & 2323.238 & 2323.157 & d4 & $2-4,6,7,9,10$ & - & $2-10$ & - \\
\hline \multicolumn{11}{|c|}{ Oxidation of M76 } \\
\hline \multirow[t]{2}{*}{$76-86$} & $19-25$ & K77 & K20 & 2335.112 & 2335.118 & do & $2-8$ & - & $3-10$ & - \\
\hline & & & & 2339.137 & 2339.143 & $\mathrm{~d} 4$ & $2-8$ & - & $2-10$ & - \\
\hline \multirow[t]{2}{*}{$91-106$} & $19-25$ & K94 & K20 & 2721.384 & 2721.397 & do & $3-5,7-13,15$ & - & $2-14$ & - \\
\hline & & & & 2725.409 & 2725.411 & d4 & $3-15$ & & $2-15$ & - \\
\hline \multicolumn{11}{|c|}{ Ammonia loss } \\
\hline \multirow[t]{2}{*}{ 91-106 } & $19-25$ & K94 & K20 & 2704.357 & 2704.367 & do & $4-15$ & - & $2-12,15$ & - \\
\hline & & & & 2708.382 & 2708.387 & d4 & $4-15$ & - & $2-12$ & - \\
\hline \multicolumn{11}{|c|}{ Peptides modified by hydrolyzed cross-linker } \\
\hline $\mathrm{CaM}$ & & modified residue & & 1958.923 & 1958.929 & do & $2-16$ & - & $2-16$ & - \\
\hline 14-30 & & K21 & & 1962.948 & 1962.951 & d4 4 & $2-16$ & - & $2-16$ & $\begin{array}{c}- \\
\text { (Continued) }\end{array}$ \\
\hline
\end{tabular}


Table 4. Continued

\begin{tabular}{|c|c|c|c|c|c|c|c|c|c|c|}
\hline \multicolumn{2}{|c|}{ Modified sequence } & \multicolumn{2}{|c|}{ Modified residue } & \multirow{2}{*}{$\begin{array}{c}\text { Theoretical } \\
\text { precursor } \\
\text { mass }\end{array}$} & \multirow{2}{*}{ 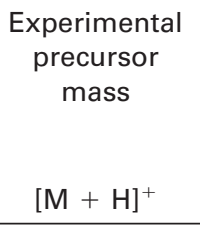 } & \multirow[t]{2}{*}{ Cross-linker $\mathrm{BS}^{2} \mathrm{G}$} & \multicolumn{4}{|c|}{ Identified fragment ions } \\
\hline CaM & AC8 peptide & $\mathrm{CaM}$ & AC8 peptide & & & & b ion series CaM & $\begin{array}{c}\text { AC } 8 \\
\text { peptide }\end{array}$ & y ion series $\mathrm{CaM}$ & $\begin{array}{c}\text { AC8 } \\
\text { peptide }\end{array}$ \\
\hline \multirow[t]{2}{*}{ 14-37 } & - & K21 & - & 2745.329 & 2745.322 & d0 & $3-10,12-14,16-23$ & - & $16,18,19,21$ & - \\
\hline & & & & 2749.354 & 2749.361 & $\mathrm{~d} 4$ & $3-23$ & - & $2-7,9-15,17-21,23$ & - \\
\hline \multirow[t]{2}{*}{-} & - & K30 & - & 2745.329 & 2745.322 & d0 & $3-7,9-11,13-23$ & - & $2-11,13-16,18,19,21$ & - \\
\hline & & & & 2749.354 & 2749.361 & $\mathrm{~d} 4$ & $3-7,9-23$ & - & $2-8,10-21,23$ & - \\
\hline \multicolumn{11}{|c|}{ Ammonia loss } \\
\hline \multirow[t]{2}{*}{ 14-37 } & - & K21 & - & 2728.302 & 2728.315 & d0 & $4-10,11,13-23$ & - & $2-23$ & - \\
\hline & & & & 2732.327 & 2732.347 & d4 & $6,6,7,9-23$ & - & $2-10,12,14-23$ & - \\
\hline \multirow[t]{2}{*}{-} & - & K30 & - & 2728.302 & 2728.315 & d0 & $4-12,14,15,17-23$ & - & $2-23$ & - \\
\hline & & & & 2732.327 & 2732.347 & $\mathrm{~d} 4$ & $3,6-10,12-23$ & - & $2-7,9,11-15,16,18-23$ & - \\
\hline \multicolumn{11}{|c|}{ Oxidation of M36 } \\
\hline \multirow[t]{2}{*}{ 14-37 } & - & K21 & - & 2761.328 & 2761.334 & $\mathrm{~d} 0$ & $3,5-10,12-23$ & - & $2-7,9-12,15-22$ & - \\
\hline & & & & 2765.353 & 2765.351 & d4 & $3-10,12,14-23$ & - & $2-7,10,12,14,17-23$ & - \\
\hline \multirow[t]{2}{*}{-} & - & K30 & - & 2761.328 & 2761.334 & d0 & $3,5-23$ & - & $2-12,14,16-18,20,21$ & - \\
\hline & & & & 2765.353 & 2765.351 & $\mathrm{~d} 4$ & $3-11,13-23$ & - & $2-7,9-14,16-18,20-22$ & - \\
\hline \multicolumn{11}{|c|}{ Oxidation of M36 and ammonia loss } \\
\hline \multirow[t]{2}{*}{ 14-37 } & - & K21 & - & 2744.301 & 2744.321 & $\mathrm{~d} 0$ & $3-6,8-10,12,14,16-23$ & - & $2-7,10-21,23$ & - \\
\hline & & & & 2748.326 & 2748.344 & d4 & $3-6,9,10,12,15-23$ & - & $2-7,9-22$ & - \\
\hline \multirow[t]{2}{*}{-} & - & K30 & - & 2744.301 & 2744.321 & do & $3-23$ & - & $2-13,15-23$ & - \\
\hline & & & & 2748.326 & 2748.344 & d4 & $3-6,8-14,17-23$ & - & $2-8,10,11,13-22$ & - \\
\hline \multicolumn{11}{|c|}{ Oxidation of M36, two cross-linkers } \\
\hline \multirow[t]{4}{*}{ 14-37 } & - & $\mathrm{K} 21, \mathrm{~K} 30$ & - & 2875.360 & 2875.334 & $2 x \mathrm{~d} 0$ & $5,7,9-16,2$ & & $9-17,19$ & - \\
\hline & & & & 2879.385 & 2879.386 & d0 K21,d4 K30 & $3-10,12-23$ & & $2-21$ & - \\
\hline & & & & 2879.385 & 2879.386 & d4 K30,d0 K21 & $3-23$ & & $2-13,15,17-21$ & - \\
\hline & & & & 2883.410 & 2883.419 & $2 x d 4$ & $3-9,11-23$ & & $2-15,17-23$ & - \\
\hline \multirow[t]{2}{*}{$22-37$} & - & K30 & - & 1807.874 & 1807.880 & d0 & $3-15$ & & $2-11,13,14$ & - \\
\hline & & & & 1811.899 & 1811.904 & d4 & $3-15$ & & $2-15$ & - \\
\hline \multicolumn{11}{|c|}{ Oxidation of M36 } \\
\hline \multirow[t]{2}{*}{ 22-37 } & - & K30 & - & 1823.873 & 1823.874 & d0 & $3-15$ & - & $2-15$ & - \\
\hline & & & & 1827.898 & 1827.896 & d4 & $4-15$ & - & $2-15$ & - \\
\hline \multirow[t]{2}{*}{ 75-86 } & - & K75 & - & 1594.727 & 1594.730 & d0 & $1-11$ & - & $2-11$ & - \\
\hline & & & & 1598.752 & 1598.755 & d4 & $1-11$ & - & $2-11$ & - \\
\hline \multirow[t]{2}{*}{-} & - & K77 & - & 1594.727 & 1594.730 & d0 & $2-11$ & - & $2-11$ & - \\
\hline & & & & 1598.752 & 1598.755 & d4 & $2-11$ & - & $2-11$ & - \\
\hline
\end{tabular}


Table 4. Continued

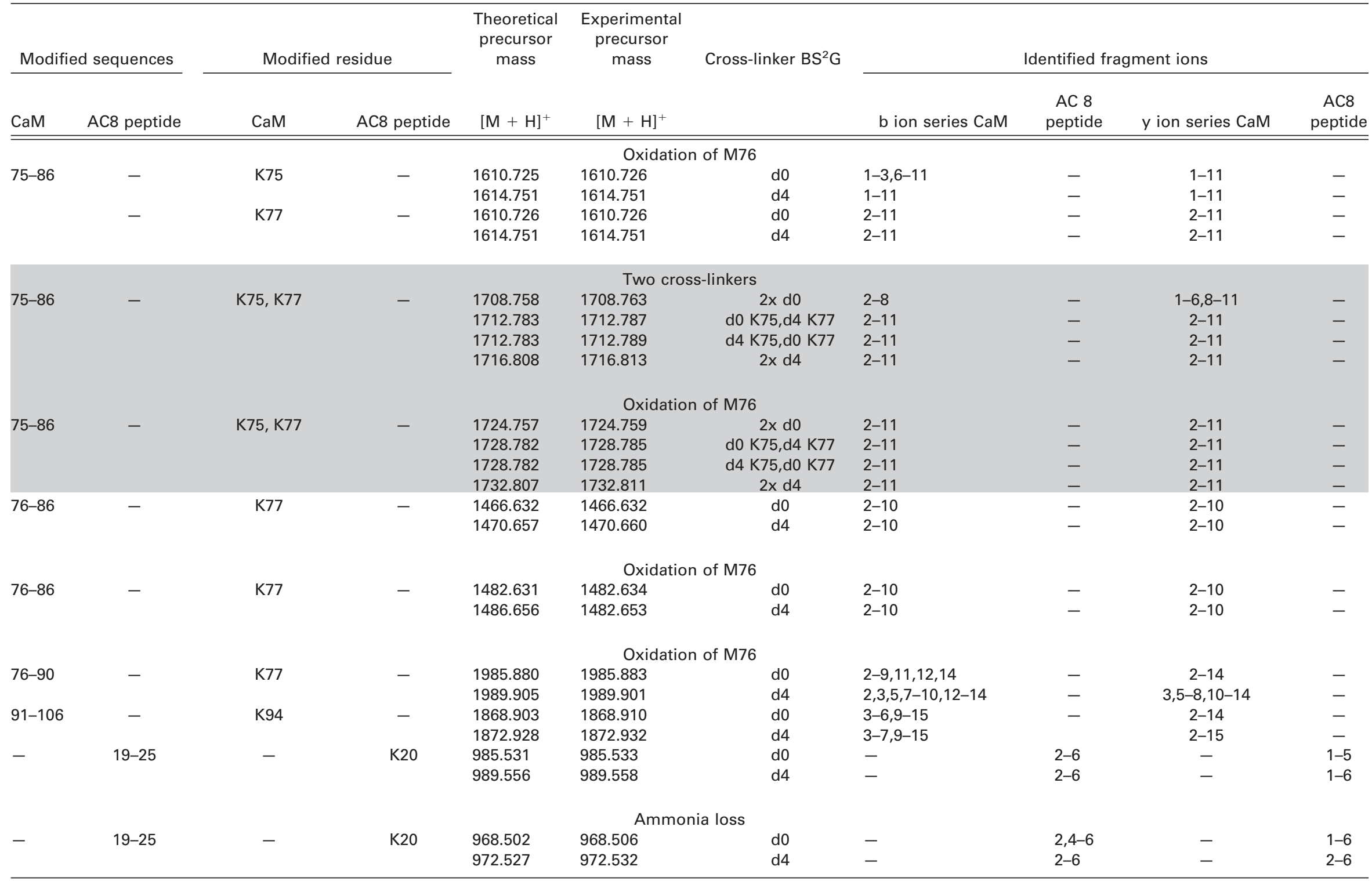




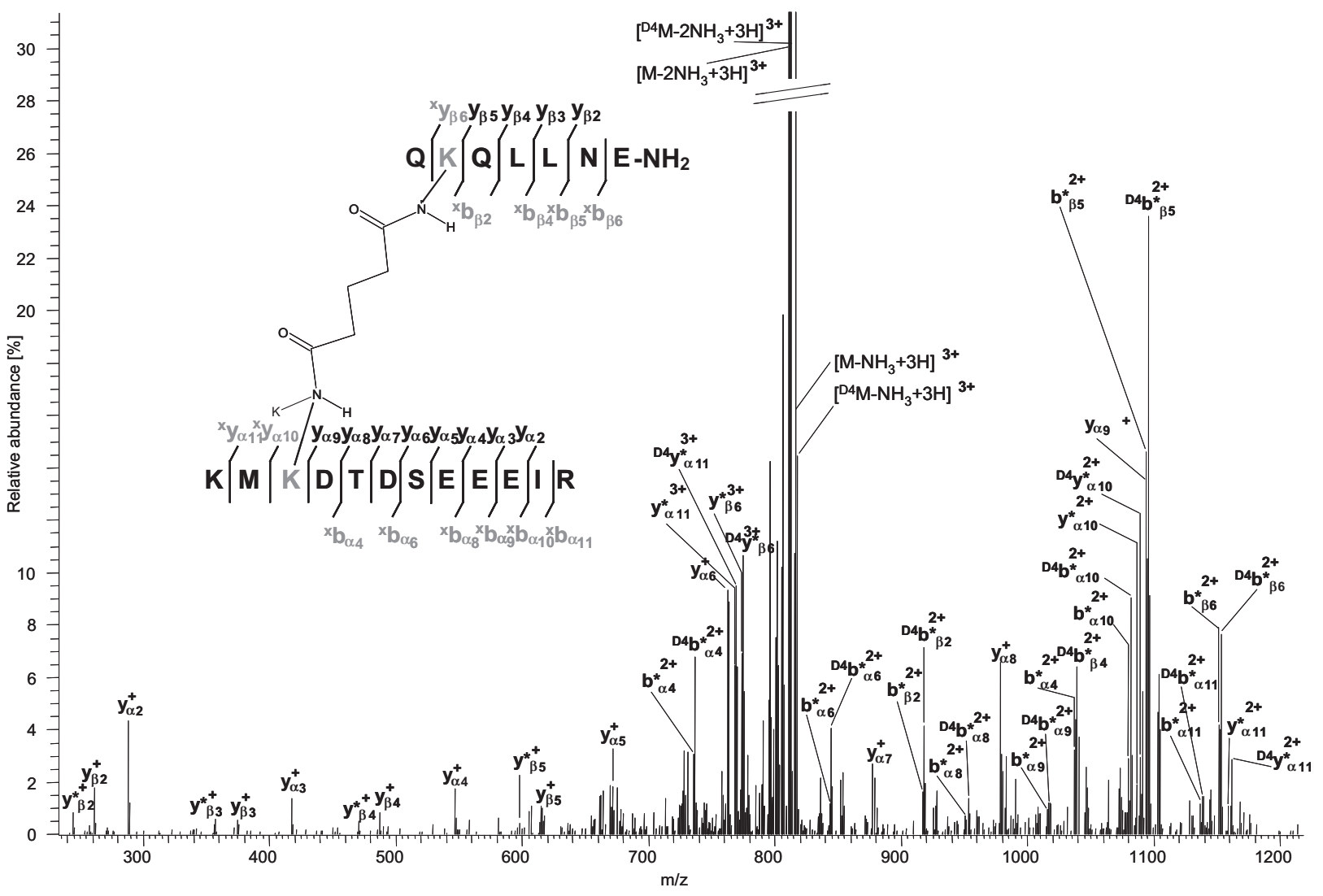

Figure 5. Product ion spectrum of the signal at $m / z 823.08\left([\mathrm{M}+3 \mathrm{H}]^{3+}\right)$ corresponding to a cross-linked product between CaM (amino acids 75 to 86, M-76 oxidized, lower sequence) and AC8 peptide (amino acids 19 to 25 , upper sequence) cross-linked with 100 -fold excess $\mathrm{BS}^{2} \mathrm{G}-d_{4}, 1 \mathrm{mM}$ EGTA, reaction time $30 \mathrm{~min}$. Isolation of the precursor ion with an isolation window of $3 \mathrm{u}$ also includes the cross-linked product with $\mathrm{BS}^{2} \mathrm{G}-d_{0}$. Ions consisting of one peptide fragment plus cross-linker and the intact cross-linked peptide are printed in grey and are denoted in the amino acid sequence as ${ }^{x} b$ or ${ }^{x} y$ ions, respectively. Fragment ions that are created by an additional loss of ammonia are indicated as $\mathrm{y}^{*}$ and $\mathrm{b}^{*}$ ions.

between CaM and AC8 peptide is concerned, MS/MS data pointed to lysine residues at positions 75 and 77 in the central $\alpha$-helix of CaM, Lys-21, and Lys-30 in the $\mathrm{N}$-terminal lobe of CaM, and Lys-94 in the C-terminal lobe of CaM to be cross-linked with Lys-20 in the AC8 peptide (Table 4). In Figure 5, the product ion spectrum of the triply charged ion of the cross-linked product between CaM (amino acids 75 to 86, Met-76 oxidized)

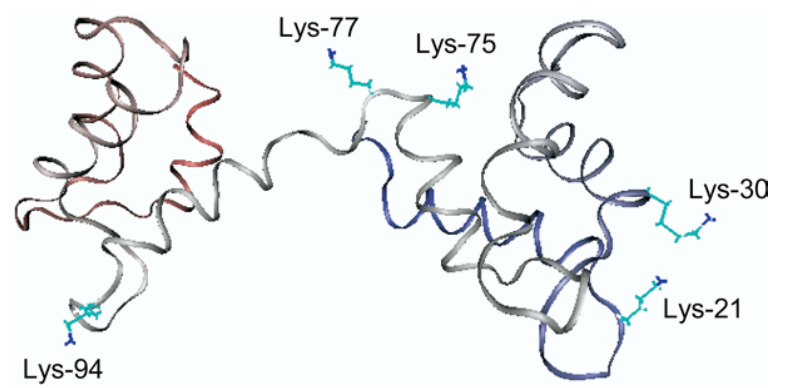

Figure 6. NMR structure of calcium-free CaM (pdb entry 1DMO) with the side chains of lysines indicated that were found to be cross-linked with the AC8 peptide and AC8 peptide (amino acids 19 to 25), is presented. For both peptides comprising the cross-linked product, nearly complete y type ion series and a number of $b$ type ions were observed, with the fragmentation patterns unambiguously identifying Lys-77 of CaM as the amino acid to be cross-linked with Lys-20 of the AC8 peptide. In total, MS/MS information was obtained for six intermolecular cross-linked products, with a number of cross-linked products being also present as oxidized species (Met-76 oxidized). Moreover, ammonia loss from the precursor ion was frequently observed in the product ion spectra. Three of the six intermolecular cross-linked products revealed cross-links between Lys-75 or Lys-77 of CaM with lysine 20 of the AC8 peptide (Table 4). One cross-linked product was found for each of the CaM lysine residues at positions 21, 30, or 94 with Lys-20 of the AC8 peptide. MS/MS analysis of peptides that had been modified by a partially hydrolyzed cross-linker revealed the same lysines that had already been found to be involved in intermolecular cross-linking (Lys-21, Lys-30, Lys-75, Lys-77, and Lys-94 of CaM and Lys-20 of AC8 peptide) (Table 4). 
MS/MS experiments exposed that a number of crosslinked products had been created, in which two crosslinker molecules are present (Table 4 , shaded areas)thus making the complexity of created cross-linked species even more fascinating. For these species, the isotope pattern obviously is 1:2:1. Here, the first crosslinker molecule connects two amine groups of the binding partners, whereas the second cross-linker molecule is partially hydrolyzed due to the absence of a suitable amine group in the correct cross-linking distance. In the present case, either Lys-75 or Lys-77 reacted with Lys-20 in the AC8 peptide, whereas the second cross-linker molecule reacted at the remaining free lysine on one site and was hydrolyzed at its other reactive site (Table 4). All possible combinations of cross-linked species with incorporated nondeuterated and four-times deuterated cross-linkers were observed.

\section{Structure of the Calcium-Free CaM/AC8 Peptide Complex}

In Figure 6, an NMR structure of calcium-free CaM (apo-CaM) is presented, in which the side chains of these lysines are indicated that have been found to be involved in intermolecular cross-linking between CaM and the AC8 peptide based on MS/MS experiments. The intermolecular constraints found for the homobifunctional amine-reactive cross-linkers $\mathrm{BS}^{2} \mathrm{G}$ and $\mathrm{BS}^{3}$ (spacer lengths 7.7 and $11.4 \AA$, Table 1) point conclusively to Lys-75 or Lys-77 of the central $\alpha$-helix of CaM as well as Lys-21 and Lys-30 in the $\mathrm{N}$-terminal lobe, and Lys-94 in the C-terminal lobe of CaM to be cross-linked with Lys-20 of the AC8 peptide. One drawback of the present study consists in that only a few reactive sites (N-terminus and Lys-20) are present in the AC8 peptide, thus reducing the number of possibly created cross-linked products. For future studies, cross-linking reagents with different specificities, such as photoreactive cross-linkers, should be evaluated [13]. Without conducting further cross-linking studies, we are presently unable to propose a structural model of the CaM/AC8 peptide complex. From the calcium-free structure of CaM (Figure 6), one could envision that Lys-20 of the AC8 peptide is in the correct distance to CaM lysines at positions 21, 30, 75, and 77 to be cross-linked by $\mathrm{BS}^{2} \mathrm{G}$ and $\mathrm{BS}^{3}$. However, the observed cross-linked product between Lys-94 of CaM and Lys-20 of the AC8 peptide is not in agreement with the proposed arrangement. Further cross-linking studies will reveal if the AC8 peptide might even bind to CaM in different orientations.

\section{Conclusions}

The combination of employing isotope-labeled crosslinkers and a mass spectrometric technique yielding data with high mass accuracy has proven to be extremely powerful in rapidly identifying cross-linker containing species from the complex peptide mixtures created from enzymatic digestion of the cross-linking reaction mixtures. In case more than one reactive functional group, e.g., $\varepsilon$-amine groups of lysine residues, is present in a sequence stretch, an in-depth MS/MS analysis is essential for unambiguously identifying sites of modification. Further cross-linking studies will have to be conducted to propose a structural model for the CaM/AC8 peptide complex, which is formed in the absence of calcium.

\section{Acknowledgments}

The authors are indebted to Pierce Inc. for the generous gift of isotope-labeled cross-linkers $\mathrm{BS}^{3}$ and $\mathrm{BS}^{2} \mathrm{G}$. The junior research group of AS is funded by the Saxon State Ministry of Higher Education, Research, and Culture and the Deutsche Forschungsgemeinschaft (DFG project Si 867/7-1). Financial support from the Thermo Electron Corporation (Mattauch-Herzog award of the German Society for Mass Spectrometry to AS) is also gratefully acknowledged.

\section{References}

1. Sinz, A. Chemical Cross-Linking and Mass Spectrometry for Mapping Three-Dimensional Structures of Proteins and Protein Complexes. J. Mass Spectrom. 2003, 38, 1225-1237.

2. Back J. W.; de Jong, L.; Muijsers, A. O.; de Koster, C. G. Chemical Cross-Linking and Mass Spectrometry for Protein Structural Modeling. J. Mol. Biol. 2003, 331, 303-313.

3. Sinz, A. Chemical Cross-Linking and FTICR Mass Spectrometry for Protein Structure Characterization. Anal. Bioanal. Chem. 2005, 381, 44-47.

4. Karas, M; Hillenkamp, F. Laser Desorption Ionization of Proteins with Molecular Masses Exceeding 10,000 Da. Anal. Chem. 1988, 60, 22992301

5. Fenn, J. B.; Mann, M.; Meng, C. K.; Wong, S. F.; Whitehouse, C. M. Electrospray Ionization for Mass Spectrometry of Large Biomolecules. Science 1989, 46, 64-71.

6. Müller, D. R.; Schindler, P.; Towbin, H.; Wirth, U.; Voshol, H.; Hoving S.; Steinmetz, M. O. Isotope-Tagged Cross-Linking Reagents. A New Tool in Mass Spectrometric Protein Interaction Analysis. Anal. Chem. 2001, 73, 1927-1934.

7. Collins, C. J.; Schilling, B.; Young, M. M.; Dollinger, G.; Guy, R. K. Isotopically Labeled Crosslinking Reagents: Resolution of Mass Degeneracy in the Identification of Cross-Linked Peptides. Bioorg. Med. Chem. Lett. 2003, 13, 4023-4026.

8. Taverner, T.; Hall, N. E.; O'Hair, R. A. J.; Simpson, R. J. Characterization of an Antagonist Interleukin-6 Dimer by Stable Isotope Labeling, Cross-Linking, and Mass Spectrometry. J. Biol. Chem. 2002, 277, 4648746492.

9. Bennett, K. L.; Kussmann, M.; Bjork, P.; Godzwon, M.; Mikkelsen, M.; Sorensen, P.; Roepstorff, P. Chemical Cross-Linking with Thiolcleavable Reagents Combined with Differential Mass Spectrometric Peptide Mapping-A Novel Approach to Assess Intermolecular Protein Contacts. Protein Sci. 2000, 9, 1503-1518.

10. Sinz, A.; Wang, K. Mapping Protein Interfaces with a Fluorogenic Cross-Linker and Mass Spectrometry: Application to NebulinCalmodulin Complexes. Biochemistry 2001, 40, 7903-7913.

11. Tang, X.; Munske, G. R.; Siems, W. F.; Bruce, J. E. Mass Spectrometry Identifiable Cross-Linking Strategy for Studying Protein-Protein Interactions. Anal. Chem. 2005, 77, 311-318.

12. Sinz, A.; Kalkhof, S.; Ihling, C. Mapping Protein Interfaces by a Trifunctional Cross-Linker Combined with MALDI-TOF and ESI-FTICR Mass Spectrometry. J. Am. Soc. Mass Spectrom. 2005, 16, 1921-1931.

13. Trester-Zedlitz, M.; Kamada, K.; Burley, S. K.; Fenyö, D.; Chait, B. T.; Muir, T. W. A Modular Cross-Linking Approach for Exploring Protein Interactions. J. Am. Chem. Soc. 2003, 125, 2416-2425.

14. Hurst, G. B.; Lankford, T. K.; Kennel, S. J. Mass Spectrometric Detection of Affinity Purified Crosslinked Peptides. J. Am. Chem. Soc. 2004, 15, 832-839.

15. Comisarow, M. B.; Marshall, A. G. Fourier Transform Ion Cyclotron Resonance Spectroscopy. Chem. Phys. Lett. 1974, 25, 282-283.

16. Marshall, A. G. Milestones in Fourier Transform Ion Cyclotron Resonance Spectrometry Technique Development. Int. J. Mass Spectrom. 2000, 200, 331-356.

17. Kruppa, G. H.; Schoeniger, J. S; Young, M. M. A Top Down Approach to Protein Structural Studies Using Chemical Cross-Linking and Fourier 
Transform Mass Spectrometry. Rapid Commun. Mass Spectrom. 2003, 17, 155-162.

18. Novak, P.; Haskins, W. E.; Ayson, M. J.; Jacobsen, R. B.; Schoeniger, J. S.; Leavell, M. D.; Young, M. M.; Kruppa, G. H. Unambiguous Assignment of Intramolecular Chemical Cross-Links in Modified Mammalian Membrane Proteins by Fourier Transform-Tandem Mass Spectrometry. Anal. Chem. 2005, 77, 5101-5108.

19. Novak, P.; Young, M. M.; Schoeniger, J. S.; Kruppa, G. H. A Top-Down Approach to Protein Structure Studies Using Chemical Cross-Linking and Fourier Transform Mass Spectrometry. Eur. J. Mass Spectrom. 2003, 9, 623-631.

20. Schulz, D. M.; Ihling, C.; Clore, G. M.; Sinz, A. Mapping the Topology and Determination of a Low Resolution Three-Dimensional Structure of the Calmodulin-Melittin Complex by Chemical Cross-Linking and High-Resolution FTICR Mass Spectrometry: Direct Demonstration of Multiple Binding Modes. Biochemistry 2004, 43, 4703-4715.

21. Kalkhof, S.; Ihling, C.; Mechtler, K.; Sinz, A. Chemical Cross-Linking and High-Performance Fourier Transform Ion Cyclotron Resonance Mass Spectrometry for Protein Interaction Analysis: Application to a Calmodulin/Target Peptide Complex. Anal. Chem. 2005, 77, 495-503.
22. Crivici, A.; Ikura, M. Molecular and Structural Basis of Target Recognition by Calmodulin. Annu. Rev. Biophys. Biomol. Struct. 1995, 24, 85-116.

23. Gu, C.; Cooper, D. M. F. Calmodulin Binding Sites on Adenylyl Cyclase VIII. J. Biol. Chem. 1999, 274, 8012-8021.

24. Bähler, M.; Rhoads, A. Calmodulin Signaling via the IQ Motif. FEBS Lett. 2002, 513, 107-113.

25. Schmidt, A.; Kalkhof, S.; Ihling, C.; Cooper, D. M. F.; Sinz, A. Mapping Protein Interfaces by Chemical Cross-Linking and FTICR Mass Spectrometry: Application to a Calmodulin/Adenylyl Cyclase 8 Peptide Complex. Eur. J. Mass Spectrom. 2005, 11, 524-534.

26. Laemmli, U. K. Cleavage of Structural Proteins During Assembly of Head of Bacteriophage-T4. Nature 1970, 227, 680-685.

27. Jensen, O. N.; Shevchenko, A.; Mann, M. In: Protein Structure, A Practical Approach; Creighton, T. E., Ed.; Oxford University Press: Oxford, 1997, p 48.

28. BioAPEX User's Manual Vol. 1.1; Bruker Daltonics: Billerica, MA, 1996.

29. Peri, S.; Steen, H.; Pandey, A. GPMAW-A Software Tool for Analyzing Proteins and Peptides. Trends Biochem. Sci. 2001, 26, 687-689.

30. Hermanson, G. T. Bioconjugate Techniques; Academic Press Inc.: San Diego, 1996, pp 187-227. 